Article

\title{
Bioactivities of Lyngbyabellins from Cyanobacteria of Moorea and Okeania Genera
}

\author{
Imam Fathoni ${ }^{1}{ }^{(0)}$, Julie G. Petitbois ${ }^{1}$, Walied M. Alarif ${ }^{2}{ }^{\circledR}$, Ahmed Abdel-Lateff ${ }^{3,4}{ }^{\circledR}$, \\ Sultan S. Al-Lihaibi ${ }^{2}$, Erina Yoshimura ${ }^{5}$, Yasuyuki Nogata ${ }^{6}$, Charles S. Vairappan ${ }^{7}{ }^{\mathbb{D}}$, \\ Eti Nurwening Sholikhah ${ }^{8}$ and Tatsufumi Okino $1,9, * \mathbb{D}$ \\ 1 Graduate School of Environmental Science, Hokkaido University, Sapporo 060-0810, Japan; \\ tonythoni@gmail.com (I.F.); juliepetitbois@ees.hokudai.ac.jp (J.G.P.) \\ 2 Department of Marine Chemistry, Faculty of Marine Sciences, King Abdulaziz University, P.O. Box 80207, \\ Jeddah 21589, Saudi Arabia; walied1737@yahoo.com (W.M.A.); sallihaibi@kau.edu.sa (S.S.A.-L.) \\ 3 Department of Natural Products and Alternative Medicine, Faculty of Pharmacy, King Abdulaziz University, \\ P.O. Box 80260, Jeddah 21589, Saudi Arabia; ahmedabdellateff@gmail.com \\ 4 Department of Pharmacognosy, Faculty of Pharmacy, Minia University, Minia 61519, Egypt \\ 5 CERES, Inc., 1-4-5 Midori, Abiko, Chiba 270-1153, Japan; erinamusi@yahoo.co.jp \\ 6 Environmental Science Research Laboratory, Central Research Institute of Electric Power Industry, \\ Abiko 270-1194, Japan; noga@criepi.denken.or.jp \\ 7 Institute for Tropical Biology and Conservation, Universiti Malaysia Sabah, \\ Kota Kinabalu 88450, Sabah, Malaysia; csv@ums.edu.my \\ 8 Faculty of Medicine, Public Health, and Nursing, Universitas Gadjah Mada, Yogyakarta 55281, Indonesia; \\ etinurweningsholikhah@ugm.ac.id \\ 9 Faculty of Environmental Earth Science, Hokkaido University, Sapporo 060-0810, Japan \\ * Correspondence: okino@ees.hokudai.ac.jp; Tel.: +81-11-706-4519
}

Academic Editor: Derek J. McPhee

Received: 5 August 2020; Accepted: 1 September 2020; Published: 1 September 2020

\begin{abstract}
Cyanobacteria are reported as rich sources of secondary metabolites that provide biological activities such as enzyme inhibition and cytotoxicity. Ten depsipeptide derivatives (lyngbyabellins) were isolated from a Malaysian Moorea bouillonii and a Red Sea Okeania sp.: lyngbyabellins G (1), O (2), P (3), H (4), A (7), 27-deoxylyngbyabellin A (5), and homohydroxydolabellin (6). This study indicated that lyngbyabellins displayed cytotoxicity, antimalarial, and antifouling activities. The isolated compounds were tested for cytotoxic effect against human breast cancer cells (MCF7), for antifouling activity against Amphibalanus amphitrite barnacle larvae, and for antiplasmodial effect towards Plasmodium falciparum. Lyngbyabellins A and G displayed potent antiplasmodial effect against Plasmodium, whereas homohydroxydolabellin showed moderate effect. For antifouling activity, the side chain decreases the activity slightly, but the essential feature is the acyclic structure. As previously reported, the acyclic lyngbyabellins are less cytotoxic than the corresponding cyclic ones, and the side chain increases cytotoxicity. This study revealed that lyngbyabellins, despite being cytotoxic agents as previously reported, also exhibit antimalarial and antifouling activities. The unique chemical structures and functionalities of lyngbyabellin play an essential role in their biological activities.
\end{abstract}

Keywords: cyanobacteria; antiplasmodial; cytotoxic; antifouling; Moorea; Okeania

\section{Introduction}

Cyanobacteria are often associated with harmful algal blooms as well as their ability to produce diverse structurally and biologically active secondary metabolites, including enzyme inhibitors, antifouling, anticancer, antibiotic, or antiparasitic compounds [1,2]. Marine organisms have traditionally 
attracted the attention of many scientists in order to find potential active compounds, develop effective treatments of neglected diseases such as malaria, where the evolution of resistance of the parasite to current malaria drugs requires the discovery of new compounds with novel mechanisms of action [3], or deal with environmental problems such as those induced by biofouling by more eco-friendly coatings [4-7]. Valorizing them could lead to the potential isolation of active compounds. Moreover, cyanobacteria can be cultivated in photobioreactors with precisely controlled culture conditions producing active compounds [8].

As part of an effort to identify antiplasmodial and antifouling metabolites, two cyanobacteria from two geographically distinct environments were studied: a Malaysian Moorea bouillonii and a Red Sea Okeania sp. Moorea and Okeania genera were delineated from the Lyngbya genus $[9,10]$. As phylogenetically close genera, they produce similar compounds. In this study, the lyngbyabellin family depsipeptides were isolated from Moorea bouillonii and Okeania sp. These kinds of compounds were initially found in the sea hare Dolabella auricularia after being identified from cyanobacterial origins as part of the sea hare diet [11,12]. These depsipeptides are characterized by two thiazole rings and an unusual gem-dichloro group. Lyngbyabellins $\mathrm{G}, \mathrm{O}$, and $\mathrm{P}$ have recently been shown to inhibit the settlement of Amphibalanus amphitrite barnacle larvae. At the same time, such compounds are reported as antimalarial agents [13]. The number of marine natural products which were tested against Plasmodium is limited but increasing. Several compounds show promising activities as future antimalarial agents [5] (Table 1). Dolastatin 10, a peptide microtubule inhibitor isolated from D. auricularia, is considered as the most potent antimalarial compound of cyanobacteria (IC50 $=0.1 \mathrm{nM})$. Despite its low selectivity index against various cancer cell lines $(\leq 1)$, dolastatin 10 is one of the most potent anticancer drugs [14]. Other compounds showing promising activity against different types and stages of malaria were also isolated from cyanobacteria such as dolastatin 15 , gallinamide $\mathrm{A}$, hoshinoamide A, carmabin A, dragomabin, venturamide A, and companeramide A [15-20]. Moorea and Okeania genera already provided several antimalarial molecules, including mabunamide, ikoamide, kakeromamide B, ulongamide A, lyngbyabellin A, and bastimolides A and B [13,21-24].

Table 1. Structural diversity and antimalarial potential of secondary metabolites derived from cyanobacteria.

\begin{tabular}{|c|c|c|c|c|c|}
\hline Compounds & Sources & Structural Class & $\mathrm{IC}_{50}(\mu \mathrm{M})$ & $\begin{array}{c}\text { Assay } \\
\text { Method }\end{array}$ & References \\
\hline Dolastatin 10 & $\begin{array}{c}\text { Dolabella } \\
\text { auricularia }\end{array}$ & peptide & 0.0001 & pLDH & [15] \\
\hline Dolastatin 15 & Symploca sp. & peptide & 0.0024 & $\mathrm{pLDH}$ & [15] \\
\hline Gallinamide A & Schizotrix sp. & depsipeptide & 8.4 & Pico-Green & [16] \\
\hline Hoshinoamide A & Caldora penicillate & lipopeptides & 5.2 & $\mathrm{pLDH}$ & [17] \\
\hline Carmabin A & $\begin{array}{l}\text { Lyngbya. } \\
\text { majuscula }\end{array}$ & lipopeptides & 4.3 & Pico-Green & [18] \\
\hline Dragomabin & L. majuscula & lipopeptides & 6.0 & Pico-Green & [18] \\
\hline Venturamide A & Oscillatoria sp. & hexapeptides & 8.2 & Pico-Green & [19] \\
\hline Companeramide A & Leptolyngbya & depsipeptide & 5.7 & Sybr Green & [20] \\
\hline Mabunamide & Okeania sp. & lipopeptides & 1.4 & pLDH & [21] \\
\hline Ikoamide & Okeania sp. & lipopeptides & 0.14 & pLDH & [22] \\
\hline Kakeromamide B & Moorea producens & pentapeptides & 8.9 & Sybr Green & [13] \\
\hline Ulongamide A & M. producens & depsipeptides & 0.99 & Sybr Green & [13] \\
\hline Lyngbyabellin A & M. producens & depsipeptides & 0.0015 & Sybr Green & [13] \\
\hline Bastimolide A & Okeania hirsuta & $\begin{array}{l}\text { polyhydroxy } \\
\text { macrolide }\end{array}$ & 0.27 & Sybr Green & [23] \\
\hline Bastimolide B & O. hirsuta & macrolide & 5.7 & Pico-Green & [24] \\
\hline
\end{tabular}

\section{Results and Discussion}

\subsection{Isolation and Characterization of Compounds}

The MeOH extracts of Okeania sp. and M. bouillonii were partitioned between EtOAc and $\mathrm{H}_{2} \mathrm{O}$. The EtOAc fraction was separated into nine subfractions via normal phase silica gel column 
chromatography. The fractions obtained were subjected to Liquid Chromatography-Electrospray Ionization- Mass Spectrometry (LC-ESI-MS) analysis. All isolated compounds (Figure 1) provided 9:6:1 isotope peaks, revealing the presence of two chlorine atoms. Compounds 1-3 were previously isolated from this Okeania sp. (Saudi Arabia) extract [25], together with compounds 4 and 5. Compounds 6 and 7 were isolated from the other cyanobacterium, M. bouillonii (Malaysia). The identities of the additional compounds $\mathbf{4} \mathbf{- 7}$ were confirmed by comparison with the chemical shifts reported in the literature [12,26-28].

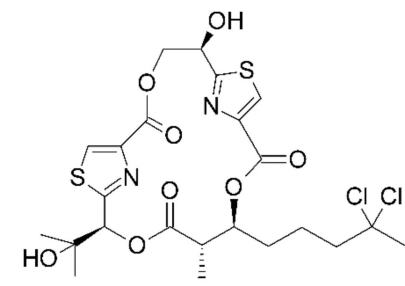

Lyngbyabellin $\mathrm{G}(\mathbf{1})$

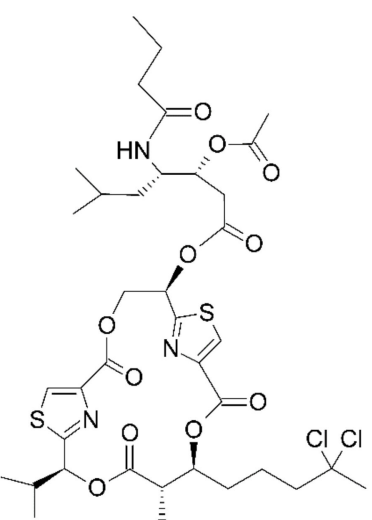

Lyngbyabellin H (4)

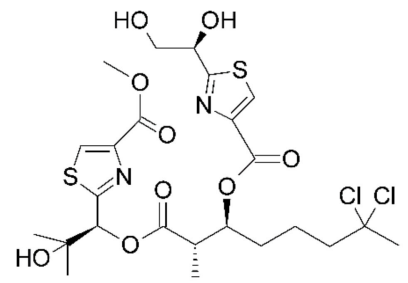

Lyngbyabellin O (2)

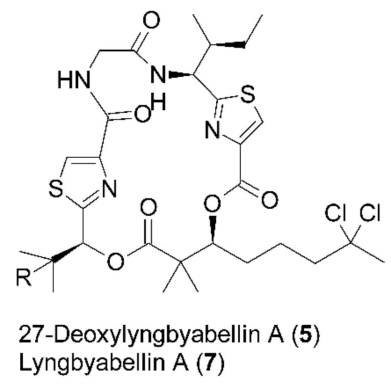

Lyngbyabellin A (7)

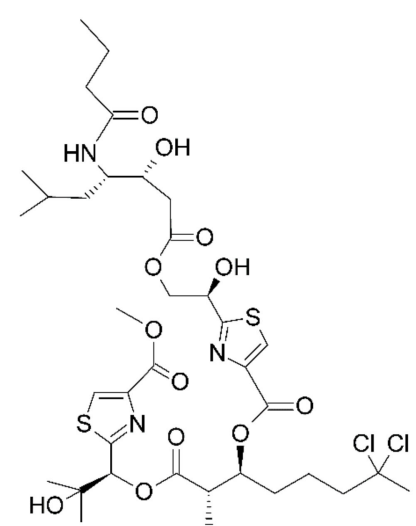

Lyngbyabellin $\mathrm{P}$ (3)

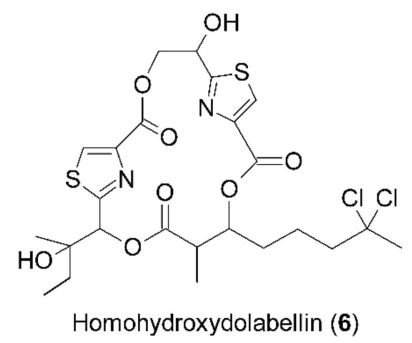

Figure 1. Structure of depsipeptides isolated for this study: lyngbyabellin $G(\mathbf{1})$, lyngbyabellin $O$ (2), lyngbyabellin P (3), lyngbyabellin H (4), 27-deoxylyngbyabellin A, R = H (5), homohydroxydolabellin (6), and lyngbyabellin $\mathrm{A}, \mathrm{R}=\mathrm{OH}$ (7). Compounds 1-5 are from Okeania sp. and 6-7 from M. bouillonii.

\subsection{Antifouling Activity}

A previous study on the antifouling activity of 1-3 showed that these compounds inhibit the settlement of $A$. amphitrite barnacle larvae [25]. Indeed, 1 showed low activity $\left(\mathrm{EC}_{50} 4.41 \mu \mathrm{g} / \mathrm{mL}\right)$, while 2 and 3 exhibited potent activity ( $\mathrm{EC}_{50} 0.24$ and $0.62 \mu \mathrm{g} / \mathrm{mL}$, respectively) after $48 \mathrm{~h}$ of exposure. In the current study, 4 was inactive at $10 \mu \mathrm{g} / \mathrm{mL}$. These results suggest that the larvae are more sensitive to the acyclic structure of $\mathbf{2}$ and $\mathbf{3}$ than the cyclic structure of $\mathbf{1}$ and $\mathbf{4}$, and that the presence of a side chain slightly decreases the activity ( $\mathbf{1}$ and $\mathbf{2}$ being more active than $\mathbf{3}$ and $\mathbf{4}$, respectively). Compound 5 was the most potent $\left(\mathrm{EC}_{50} 0.09 \mu \mathrm{g} / \mathrm{mL}\right.$ ), but its activity was related to its high toxicity (almost all the larvae were dead when exposed to $1 \mu \mathrm{g} / \mathrm{mL}$ ), probably due to the presence of two extra lactams, which is the main difference compared with the other tested lyngbyabellins. As for all the compounds, the activity remained after $120 \mathrm{~h}$ of exposure.

\subsection{Cytotoxicity}

The cytotoxicity of 1-3 with respect to MCF7 breast cancer cells was already reported in a previous study, whose $\mathrm{IC}_{50}$ were $120,>160$, and $9 \mu \mathrm{M}$, respectively [25]. In this study, the $\mathrm{IC}_{50}$ values of 4 and 5 were 0.07 and $0.31 \mu \mathrm{M}$, respectively. Compound $\mathbf{6}$ showed non-cytotoxicity with respect to MCF7 breast cancer cells. These differences in cytotoxicity were attributed to the dissimilarities in their 
structures. Cyclic lyngbyabellin with a side chain (4) is the most active, while an acyclic form or the lack of a side chain decreases cytotoxicity [12].

\subsection{Antiplasmodial Activity}

Compound 1 isolated from Okeania sp., and compounds $\mathbf{6}$ and $\mathbf{7}$ from M. bouillonii were tested against the malaria parasite (P. falciparum). Compounds 1 and $\mathbf{7}$ were active towards the malaria parasite ( $\mathrm{IC}_{50} 1.1$ and $0.3 \mu \mathrm{M}$, respectively), while 6 was moderately active ( $\left.\mathrm{IC}_{50} 6.4 \mu \mathrm{M}\right)$. The antiplasmodial activity of compound 7 is less potent than what was reported by Sweeney-Jones et al. [13]. This is presumably because compound 7 exhibits a better inhibition towards the liver stage of Plasmodium compared to the intraerythrocytic stage used in this research. The assay was repeated three times in the concentration range of $0.05-10(\mu \mathrm{g} / \mathrm{mL})$. It is noteworthy that the mechanisms of antiplasmodial compounds isolated from M. bouillonii impeding the growth of Plasmodium are still unclear. According to Peatey et al. [29], until recently, most of the antimalarial drugs developed only blocked the asexual stage of parasites. However, as $\mathbf{1}$ and $\mathbf{7}$ were reported as cytotoxic towards cancer cells, we hypothesized that they act in the same way on erythrocytes, which distorts the results of the antimalarial assay.

\section{Materials and Methods}

\subsection{Cyanobacteria Collection}

Okeania sp. was collected on the Algetah Alkabira reef near Jeddah, Saudi Arabia (N 21 ${ }^{\circ} 41^{\prime} 23.98^{\prime \prime}$; E 39 $00^{\prime} 52.94^{\prime \prime}$ ) in April 2015, while Moorea bouillonii was collected in March 2014 and September 2016 at Sabah, Malaysia. Foreign particles were removed by hand and both cyanobacterial extracts were squeezed by hand to remove any seawater before being stored in $\mathrm{MeOH}$ for transportation.

\subsection{Identification of Cyanobacteria}

A small portion of the materials was also preserved in $10 \mathrm{~mL}$ of RNAlater solution for genetic analysis. Voucher specimens of Okeania sp. (S1501) and M. bouillonii (M1415) preserved in RNAlater were deposited at Hokkaido University, Japan.

\subsection{Extraction and Isolation of Compounds}

Both extracts were homogenized and extracted three times with $\mathrm{MeOH}$. The dried $\mathrm{MeOH}$ extracts were then partitioned between EtOAc and $\mathrm{H}_{2} \mathrm{O}(1: 1, v / v)$. The isolation of lyngbyabellins $\mathrm{G}(\mathbf{1}), \mathrm{O}(\mathbf{2})$, and P (3) from this Okeania sp. extract was previously reported [25]. Briefly, the dried EtOAc fraction was purified by NP-column chromatography over silica gel. A stepwise gradient composed of hexane and EtOAc, followed by EtOAc and $\mathrm{MeOH}$, was used to elute the lyngbyabellins. The 75:25 EtOAc/MeOH fraction was fractionated by RP-HPLC over a Cosmosil Cholester column $(10 \times 250 \mathrm{~mm}, 5 \mu \mathrm{m}$; gradient 0-50 min, 75-90\% MeCN containing 0.05\% (v/v) trifluoroacetic acid (TFA), UV detection at $210 \mathrm{~nm}$, and flow rate of $3 \mathrm{~mL} / \mathrm{min}$ ) to obtain 1, 2, and 3 (3.0, 1.8, and $2.0 \mathrm{mg}$, respectively). Lyngbyabellins $\mathrm{H}$ (4) and 27-deoxylyngbyabellin A (5) were isolated from the 4:6 hexane/EtOAc. This fraction was purified by the same HPLC system (gradient 0-60 min, 50-70\% MeCN). The subfraction was eluted at $t_{R} 46.1-46.5 \mathrm{~min} ; 3.0 \mathrm{mg}$ was further purified by RP-HPLC (gradient 0-60 $\mathrm{min}: 50-70 \% \mathrm{MeCN}$ ) to provide $5\left(t_{\mathrm{R}} 36.3 \mathrm{~min}, 1.6 \mathrm{mg}\right)$ and $\mathbf{4}\left(\mathrm{t}_{\mathrm{R}} 38.9 \mathrm{~min}, 1.1 \mathrm{mg}\right)$.

Homohydroxydolabellin (6), a dichlorinated compound, was isolated from fraction EtOAc $100 \%$ and EtOAc/MeOH 75:25 of M. bouillonii. The compound produced $[\mathrm{M}+\mathrm{H}]^{+}$peaks at $m / z 641.1089$ $\left(t_{R} 5.4-5.8 \mathrm{~min}\right.$ ) and the yield was $1.1 \mathrm{mg}$. The compound was further purified by HPLC (isocratic $40 \% \mathrm{MeCN}$, flow rate $1 \mathrm{~mL} / \mathrm{min}$, column Cosmosil Cholester $4.6 \times 250 \mathrm{~mm}$, wavelength $210 \mathrm{~nm}$ ). The final amount of the compound was $0.6 \mathrm{mg}$. Lyngbyabellin A (7) was also isolated from this fraction, similar to the method previously described $\left(t_{R} 13.3-14.6 \mathrm{~min}, 0.5 \mathrm{mg}\right)$. The identity of the compounds was confirmed by a combination of ${ }^{1} \mathrm{H}$ NMR spectroscopy $\left(\mathrm{CDCl}_{3}, 400 \mathrm{MHz}\right)$ and $\mathrm{MS}$ analysis (Supplementary Materials: Tables S1-S4 and Figures S5-S8). In our previous study, the identity 
of $\mathbf{1}$ was confirmed by comparison of ${ }^{1} \mathrm{H}$ and ${ }^{13} \mathrm{C}$ NMR data with the literature (the largest difference in ${ }^{13} \mathrm{C}$ chemical shifts was $\left.0.0028 \mathrm{ppm}\right)$, together with similar specific rotation $\left([\alpha]^{26}{ }_{\mathrm{D}}-28.6\right.$ for $\mathbf{1}$ and -26 reported for lyngbyabellin G) [12,25]. As compounds 1-5 were isolated from the same organism, their configurations were assumed to be identical.

\subsection{Antifouling Assay on A. amphitrite}

The antifouling activity of the compounds was determined according to a procedure reported previously [25]. Briefly, the newly developed cyprids of $A$. amphitrite were tested against several different concentrations of the isolated compounds $(\mathbf{1}-\mathbf{5})(0.03-10 \mu \mathrm{g} / \mathrm{mL})$ in triplicate $(\mathrm{n}=3)$. The assays were conducted using 24-well polystyrene culture plates, with each well containing $2 \mathrm{~mL}$ seawater and six cyprids. After $48 \mathrm{~h}$ exposure to darkness, the numbers of cyprids that settled or did not settle were counted under a light microscope. The total number of dead cyprids was counted after $120 \mathrm{~h}$ of exposure. Antifouling activity was expressed as an $\mathrm{EC}_{50}$ according to Probit analysis. $\mathrm{CuSO}_{4}$ was used as a positive control and $80 \%$ filtered $(0.20 \mu \mathrm{m}$ of pore filter) natural seawater (diluted with deionized water) as a negative control.

\subsection{Cytotoxicity Assay on MCF7 Breast Cancer Cells}

The cytotoxicity of the compounds was determined according to a procedure reported previously [30]. MCF7 breast cancer cells were maintained in RPMI-1640 medium with $10 \%$ fetal bovine serum (FBS). The cells were plated into 96-well plates with a density of $1.0 \times 10^{4}$ cells per well. After $24 \mathrm{~h}$ incubation, the cells were exposed to different concentrations of compounds, with cisplatin as a positive control and with $1 \%$ filtered ethanol as a negative control. The MTT assay was conducted after $72 \mathrm{~h}$ of incubation at $37^{\circ} \mathrm{C}$ and $5 \% \mathrm{CO}_{2}$.

\subsection{Antiplasmodial Assay}

The Giemsa staining method previously described by Aydin-Schmidt [31] was used to evaluate the ability of compounds to inhibit the malaria parasite. A synchronized culture of Plasmodium falciparum strain FCR-3, the late-ring stage, was used (parasitemia 2\%) for this assay [31]. A series of compound concentrations were applied in 96-well microplates and incubated for $72 \mathrm{~h}$ at $37^{\circ} \mathrm{C}$ in a reduced oxygen atmosphere. Compounds 1, 6, and 7 were dissolved in DMSO and tested in triplicate at three separate times. Chloroquine was used as a positive control and cultured medium with 1\% DMSO (final concentration of solvent in all compound tested) as a negative control. Each assay was conducted in triplicate $(n=3)$. After $72 \mathrm{~h}$, the parasitic level was evaluated by Giemsa and light microscopy. The inhibition level of compounds against Plasmodium was calculated using the formula previously reported [31,32].

\section{Conclusions}

Two cyanobacteria from two distinct environments but with genetic similarities provided several derivatives of the lyngbyabellin family: M. bouillonii (Malaysia) and Okeania sp. (Saudi Arabia). These compounds are mainly known to inhibit several cancer cell lines proliferation (Table 2). We increased the scope of the bioactivities of lyngbyabellins by studying their antimalarial and antifouling activities (Table 2).

This study added more evidence that their structure affects their activity. Indeed, as previously reported, cyclic structures with a side chain are the most cytotoxic [12,25]. Lyngbyabellins are known as actin-disrupting agents, and therefore, act on the cellular microfilaments network [12,13,26,27]. This disruption leads to the impossibility of cells to enter mitosis, giving abnormal cells with two nuclei. As a result, apoptosis occurs. Erythrocytes used in antiplasmodial assays are likely affected in the same way. Thus, cytotoxicity is considered to provide the antimalarial activity of lyngbyabellins, which precludes the direct action on the parasite (non-specific mechanisms). Homohydroxydolabellin (6) showed non-cytotoxicity towards MCF7 cells ( $>50 \mu \mathrm{g} / \mathrm{mL})$ but moderate antiplasmodial activity, 
making it a potent compound to treat malaria. Further assays on the blood cells only will be performed because the challenge of developing a new treatment is finding a substance that is effective against malaria, safe to humans (not destroying erythrocytes), cheap, and easy to be produced.

Table 2. Diversity of biological activities reported for Lyngbyabellins in the literature from 2000 to 2020.

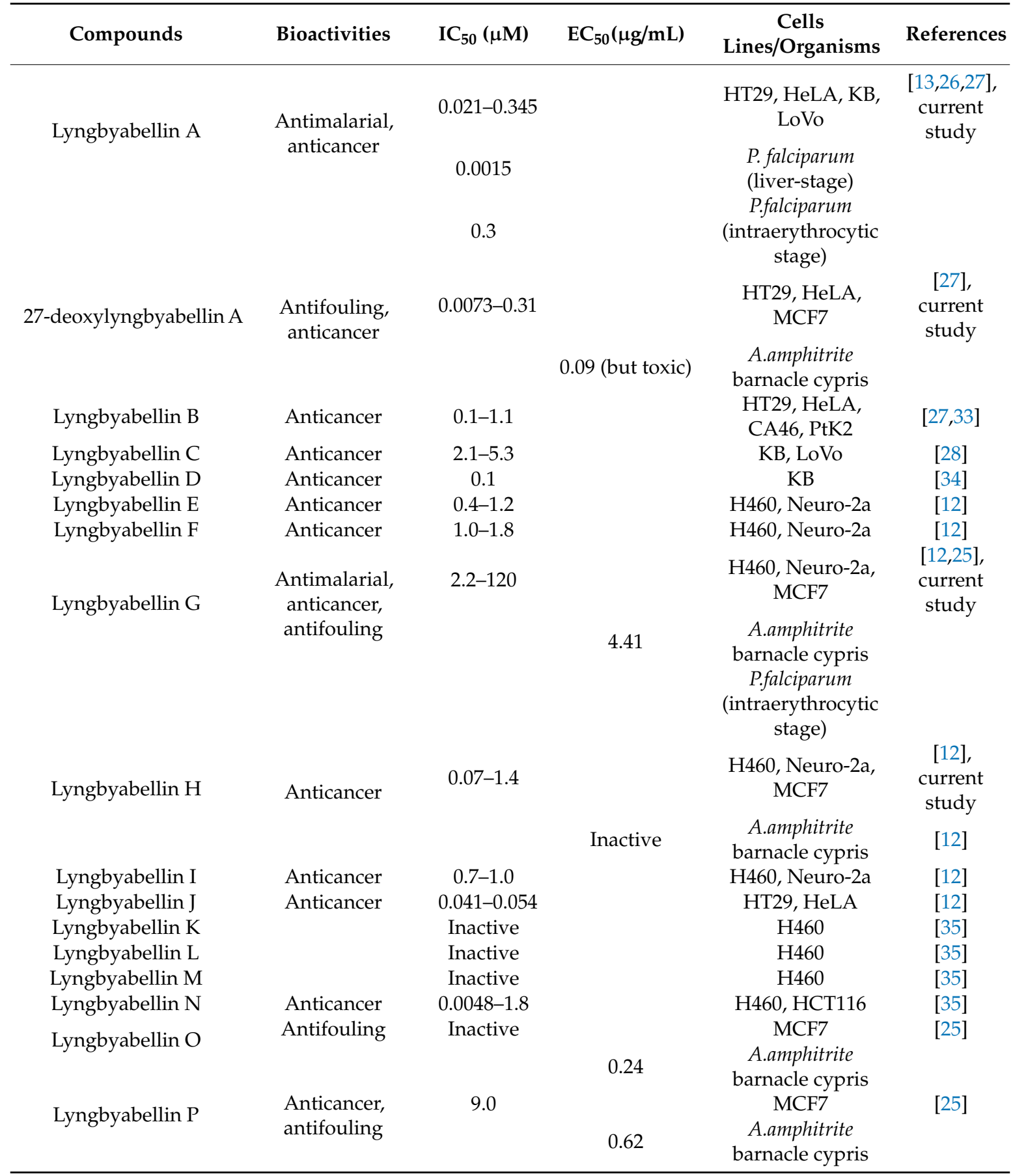

On the contrary, lyngbyabellins possessing an acyclic structure without a side chain are the most active towards the settlement of barnacle larvae. 27-deoxylyngbyabellin A (5) is the only toxic compound and the only one to have two extra lactams. Its toxicity is presumably due to this specificity. The flexibility of the acyclic structures may help interactions with a common target, while the addition of a side chain decreases them. The structures of these depsipeptides are characterized by two thiazole rings and an unusual gem-dichloro group. Currently, no structure-activity relationship antifouling 
studies have been conducted on compounds containing these features. Synthesis of more analogs for structure-activity relationship studies would improve our knowledge on their activities.

Supplementary Materials: The following are available: Tables S1-S4; tables comparison of chemical shifts of the compounds isolated in the current study with the literature values. Figures S5-S8; HPLC and LC/MS spectra of the isolation of lyngbyabellin $\mathrm{H}$, 27-hydroxylyngbyabellin $\mathrm{A}$, and homohydroxydolabellin.

Author Contributions: Conceptualization: I.F., J.G.P. and T.O.; methodology: I.F., J.G.P., W.M.A., A.A.-L., S.S.A.-L., E.Y., Y.N., C.S.V. and E.N.S.; writing original draft preparation: I.F. and J.P.G.; writing review and editing: I.F., J.P.G., T.O., W.M.A., A.A.-L, S.S.A.-L., E.Y., Y.N., C.S.V. and E.N.S. All authors have read and agreed to the published version of the manuscript.

Funding: This research was supported by JSPS KAKENHI Grant Number 16H04975 and The National Science, Technology, and Innovation Plan-the King Abdulaziz City for Science and Technology for the Kingdom of Saudi Arabia (11-ENV1540-03).

Acknowledgments: The authors would like to thank Kurasaki, M. and Kumaki, Y. from Hokkaido University, Japan, for allowing us to use the cell culture facility and the High-Resolution NMR laboratory, respectively. We want to thank Eti Nurwening Sholikah and Mosa Rini Nurul Hidayati from Faculty of Medicine, Public Health, and Nursing, Universitas Gadjah Mada, for allowing and helping us in conducting antiplasmodial assay. We also want to acknowledge the research permit given by Sabah Biodiversity Center to the corresponding author to conduct the research in Sabah (permit no. JKM/MBS.1000-2/3 JLD.3(28)).

Conflicts of Interest: The authors declare no conflict of interest.

\section{References}

1. Tan, L.T.; Phyo, M.Y. Marine cyanobacteria: A source of lead compounds and their clinically-relevant molecular targets. Molecules 2020, 25, 2197. [CrossRef] [PubMed]

2. Al-Awadhi, F.H.; Luesch, H. Targeting eukaryotic proteases for natural products-based drug development. Nat. Prod. Rep 2019, 37, 827. [CrossRef] [PubMed]

3. Tse, E.G.; Korsik, M.; Todd, M.H. The past, present and future of anti-malarial medicines. Malar. J. 2019, 18, 93. [CrossRef] [PubMed]

4. Moo-Puc, R.; Robledo, D.; Freile-Pelegrin, Y. Evaluation of selected tropical seaweeds for in vitro anti-trichomonal activity. J. Ethnopharmacol. 2008, 120, 92-97. [CrossRef]

5. Fred, M.S.; Ghee, T.T. Natural Products with Antimalarial Activity. In Phytochemistry and Pharmacognosy; Encyclopedia of Life Support Systems (EOLSS); Pezzutto, J.M., Kato, M.J., Eds.; Eolss Publishers: Oxford, UK, 2011; pp. 1-54.

6. Qi, S.; Ma, X. Antifouling compounds from marine invertebrates. Mar. Drugs. 2017, 15, 263. [CrossRef]

7. Oguri, Y.; Watanabe, M.; Ishikawa, T.; Kamada, T.; Vairappan, C.S.; Matsuura, H.; Kaneko, K.; Ishii, T.; Suzuki, M.; Yoshimura, E.; et al. New marine antifouling compounds from the red alga Laurencia sp. Mar. Drugs 2017, 15, 267. [CrossRef]

8. Johnson, T.J.; Katuwal, S.; Anderson, G.A.; Gu, L.; Zhou, R.; Gibbons, W.R. Photobioreactor Cultivation Strategies for Microalgae and Cyanobacteria. Biotechnol. Prog. 2018, 34, 811-827. [CrossRef]

9. Engene, N.; Rottacker, E.C.; Choi, H.; Byrum, T.; Kaštovský, J.H.; Ellisman, M.H.; Komárek, J.; Gerwick, W.H. Moorea producens gen. nov., sp. nov. and Moorea bouillonii comb. nov., tropical marine cyanobacteria rich in bioactive secondary metabolites. Int. J. Syst. Evol. Microbiol. 2012, 62, 1171-1178. [CrossRef]

10. Eugene, N.; Paul, V.P.; Byrum, T.; Gerwick, W.H.; Thor, A.; Ellisman, M.H. Five chemically rich species of tropical marine cyanobacteria of the genus Okeania gen. nov. (oscillatoriales, cyanoprokaryota). J. Phycol. 2013, 49, 1095-1106. [CrossRef]

11. Sone, H.; Kondo, T.; Kiryu, M.; Ishiwata, H.; Okika, M.; Yamada, K. Dolabellin, a cytotoxic bisthiazole metabolite from the sea hare Dolabella auricularia: Structural determination and synthesis. J. Org. Chem. 1995, 60, 4774-4781. [CrossRef]

12. Han, B.; McPhail, K.L.; Gross, H.; Goeger, D.E.; Mooberry, S.L.; Gerwick, W.H. Isolation and structure of five lyngbyabellin derivatives from a Papua New Guinea collection of the marine cyanobacterium Lyngbya majuscula. Tetrahedron 2005, 61, 11723-11729. [CrossRef]

13. Sweeney-Jones, A.M.; Gagaring, K.; Antonova-Koch, J.; Zhou, H.; Mojib, N.; Soapi, K.; Skolnick, J.; McNamara, C.W.; Kubanek, J. Antimalarial peptide and polyketide natural products from the Fijian marine cyanobacterium Moorea producens. Mar. Drugs 2020, 18, 167. [CrossRef] [PubMed] 
14. Pettit, G.R. The dolastatins. In Fortschritte der Chemie Organischer Naturstoffe Progress in the Chemistry of Organic Natural Products; Herz, W., Kirby, G.W., Moore, R.E., Steglich, W., Tamm, C., Eds.; Springer: Vienna, Austria, 1997; pp. 1-79. [CrossRef]

15. Fennell, B.J.; Carolan, S.; Pettit, G.R.; Bell, A. Effects of the Antimitotic Natural Product Dolastatin 10, and Related Peptides, on the Human Malarial Parasite Plasmodium falciparum. J. Antimicrob. Chemother. 2003, 51, 833-841. [CrossRef] [PubMed]

16. Linington, R.G.; Clark, B.R.; Trimble, E.E.; Almanza, A.; Luis-David, U.E.; Kyle, E.D.; Gerwick, W.H. Antimalarial peptides from marine cyanobacteria: Isolation and structural elucidation of gallinamide A. J. Nat. Prod. 2009, 72, 14-17. [CrossRef]

17. Iwasaki, A.; Tadenuma, T.; Sumimoto, S.; Shiota, I.; Matsubara, T.; Saito-Nakano, Y.; Nozaki, T.; Sato, T.; Suenaga, K. Hoshinoamides A and B, acyclic lipopeptides from the marine cyanobacterium Caldora penicillate. J. Nat. Prod. 2018, 81, 2545-2552. [CrossRef]

18. McPhail, K.L.; Correa, J.; Linington, R.G.; Gonzalez, J.; Ortega-Barría, E.; Capson, T.L.; Gerwick, W.H. Antimalarial linear lipopeptides from a panamanian strain of the marine cyanobacterium Lyngbya majuscula. J. Nat. Prod. 2007, 70, 984-988. [CrossRef]

19. Linington, R.G.; González, J.; Ureña, L.-D.; Romero, L.I.; Ortega-Barría, E.; Gerwick, W.H. Venturamides A and B: Antimalarial constituents of the panamanian marine cyanobacterium Oscillatoria sp. J. Nat. Prod. 2007, 70, 397-401. [CrossRef]

20. Vining, O.B.; Medina, R.A.; Mitchell, E.A.; Videau, P.; Li, D.; Serrill, J.D.; Kelly, J.X.; Gerwick, W.H.; Proteau, P.J.; Ishmael, J.E.; et al. Depsipeptide companeramides from a panamanian marine cyanobacterium associated with the coibamide producer. J. Nat. Prod. 2015, 78, 413-420. [CrossRef]

21. Ozaki, K.; Iwasaki, A.; Sezawa, D.; Fujimura, H.; Nozaki, T.; Saito-Nakano, Y.; Suenaga, K.; Teruya, T. Isolation and total synthesis of mabuniamide, a lipopeptide from an Okeania sp. marine cyanobacterium. J. Nat. Prod. 2019, 82, 2907-2915. [CrossRef]

22. Iwasaki, K.; Iwasaki, A.; Sumimoto, S.; Matsubara, T.; Sato, T.; Nozaki, T.; Saito-Nakano, Y.; Suenaga, K. Ikoamide, an antimalarial lipopeptide from an Okeania sp. marine cyanobacterium. J. Nat. Prod. 2020, 83, 481-488. [CrossRef]

23. Shao, C.; Linington, R.G.; Balunas, M.J.; Centeno, A.; Boudreau, P.; Zhang, C.; Engene, N.; Spadafora, C.; Mutka, T.S.; Kyle, D.E.; et al. Bastimolide A, a potent antimalarial polyhydroxy macrolide from the marine cyanobacterium Okeania hirsute. J. Org. Chem. 2015, 80, 7849-7855. [CrossRef] [PubMed]

24. Shao, C.; Mou, X.; Cao, F.; Spadafora, C.; Glukhov, E.; Gerwick, L.; Wang, C.; Gerwick, W.H. Bastimolide B, an antimalarial 24-membered marine macrolide possessing a tert-butyl group. J. Nat. Prod. 2018, 81, $211-215$. [CrossRef] [PubMed]

25. Petitbois, J.G.; Casalme, L.O.; Lopez, J.A.V.; Alarif, W.M.; Abdel-Lateff, A.; Al-Lihaibi, S.S.; Yoshimura, E.; Nogata, Y.; Umezawa, T.; Matsuda, F.; et al. Serinolamides and lyngbyabellins from an Okeania sp. cyanobacterium collected from the red sea. J. Nat. Prod. 2017, 80, 2708-2715. [CrossRef] [PubMed]

26. Luesch, H.; Yoshida, W.Y.; Moore, R.E.; Paul, V.J.; Mooberry, S.L. Isolation, structure determination, and biological activity of lyngbyabellin A from the marine cyanobacterium Lyngbya majuscula. J. Nat. Prod. 2000, 63, 611-615. [CrossRef] [PubMed]

27. Matthew, S.; Salvador, L.A.; Schupp, P.J.; Paul, V.J.; Luesch, V.J. Cytotoxic halogenated macrolides and modified peptides from the apratoxin-producing marine cyanobacterium Lyngbya bouillonii from Guam. J. Nat. Prod. 2010, 73, 1544-1552. [CrossRef] [PubMed]

28. Luesch, H.; Yoshida, W.Y.; Moore, R.E.; Paul, V.J. Structurally diverse new alkaloids from Palauan collections of the apratoxin-producing marine cyanobacterium Lyngbya sp. Tetrahedron 2002, 58, 58-7959. [CrossRef]

29. Peatey, C.L.; Leroy, D.; Gardiner, D.L.; Trenholme, K.R. Anti-malarial drugs: How effective are they against Plasmodium falciparum gametocytes? Malar. J. 2012, 11, 34. [CrossRef]

30. Lopez, J.A.V.; Al-Lihaibi, S.S.; Alarif, W.M.; Abdel-Lateff, A.; Nogata, Y.; Washio, K.; Morikawa, M.; Okino, T. Wewakazole B, a cytotoxic cyanobactin from the Cyanobacterium Moorea producens Collected in the Red Sea. J. Nat. Prod. 2016, 79, 1213-1218. [CrossRef]

31. Aydin-Schmidt, B. Giemsa staining of thick or thin blood films. In Methods in Malaria Research, 6th ed.; Moll, K., Kaneko, A., Scherf, A., Wahlgren, M., Eds.; EVIMalaR: Glasgow, UK, 2013; pp. 23-24. 
32. Fathoni, I.; Poerwanto, S.H.; Astuti, R.R.U.N.W. Bioactivity study of moss Dumortiera hirsuta (swaegr.) nees ethanolic extract on parasitemic level of Plasmodium berghei vincke and lips, 1948 in mice (Mus musculus L.). Asian J. Pharm. Clin. Res. 2017, 10, 5-8. [CrossRef]

33. Marquez, B.L.; Watts, K.S.; Yokochi, A.; Roberts, M.A.; Verdier-Pinard, P.; Jimenez, J.I.; Hamel, E.; Scheuer, P.J.; Gerwick, W.H. Structure and absolute stereochemistry of hectochlorin, a potent stimulator of actin assembly. J. Nat. Prod. 2002, 65, 866-871. [CrossRef]

34. Williams, P.G.; Luesch, H.; Yoshida, W.Y.; Moore, R.E.; Paul, V.J. Continuing studies on the cyanobacterium Lyngbya sp.: Isolation and structure determination of 15-norlyngbyapeptin A and lyngbyabellin D. J. Nat. Prod. 2003, 66, 595-598. [CrossRef] [PubMed]

35. Choi, H.; Mevers, E.; Byrun, T.; Valeriote, F.A.; Gerwick, W.H. Lyngbyabellins K-N from two Palmyra atoll collections of the marine cyanobacterium Moorea bouillonii. Eur. J. Org. Chem. 2012, 27, 5141-5150. [CrossRef] [PubMed]

Sample Availability: Samples of the compounds are not available from the authors.

(C) 2020 by the authors. Licensee MDPI, Basel, Switzerland. This article is an open access article distributed under the terms and conditions of the Creative Commons Attribution (CC BY) license (http://creativecommons.org/licenses/by/4.0/). 